\title{
DANIELLE Autonomy Education Beyond Borders
}

\begin{abstract}
This article examines whether autonomy as an educational aim should be defended at the global scale. It begins by identifying the normative issues at stake in global autonomy education by distinguishing them from the problems of autonomy education in multicultural nation-states. The article then explains why a planet-wide expansion of the ideal of autonomy is conceivable on the condition that the concept of autonomy is widened in a way that renders its precise meaning flexibly adjustable to a variety of distinct social and cultural contexts. A context-transcendent, core meaning of autonomy remains in place, however, according to which a person is only autonomous if she relates to the values and goals that direct her life in a way so that she sees them as her own and is able to identify and critically assess her principal reasons for action. Finally, the article addresses two challenges to the global expansion of autonomy education: the objection that autonomy is presently not the most important educational aim and the objection that global autonomy education is a form of cultural imperialism. It finds both objections wanting.
\end{abstract}

Keywords: autonomy; autonomy education; educational aims; cultural imperialism; global justice.

\section{Introduction}

A myriad of liberal philosophers believes that individual autonomy should be a central aim of education in liberal democratic societies (Brighouse, 2006; Callan, 2004; Curren, 2013; Gutmann, 1987; Levinson, 2002; Macedo, 1990; MacMullen, 2007; White, 1982). They do not, however, engage with the issue of whether autonomy should be a shared aim of education across the borders of their society. Their normative views seem to claim validity only within the borders of their state - or perhaps within the borders of Western societies.

This echoes to the absence of the notion of autonomy in the World Declaration on Education for All adopted in 1990 following the international Education for All conference held in Jomtien. This conference was launched by UNESCO, UNICEF, UNDP, and the World Bank. The Declaration set international goals in education as well as an agenda to meet these goals. Through the Declaration governments and international organisations committed themselves to implement educational policies and to donate resources to secure basic educational needs. The educational aims outlined in the Declaration include: (1) meeting basic learning needs 'to be able to survive, to develop [one's] full capacities, to live and work in dignity, to participate fully in development, to improve the quality of [one's] lives, to make informed decisions, and to continue learning'; (2) empowerment and the 'responsibility 
to respect and build upon [one's] collective cultural, linguistic and spiritual heritage, to promote the education of others, to further the cause of social justice, to achieve environmental protection, to be tolerant,' to ensure that 'commonly accepted humanistic values and human rights are upheld, and to work for international peace and solidarity in an interdependent world'; (3) 'the transmission and enrichment of common cultural and moral values.' The Declaration also mentions 'human development' and 'human progress,' as well as securing access to education for girls, underserved groups and the disabled. But the word 'autonomy' is conspicuously absent. Of course, one could point out that the Jomtien Declaration actually includes a conception of autonomy in all but name. For example, the aim of developing students' capacity to make informed decisions seems close to the aim of developing autonomy. However, the autonomy-related competences listed in the Declaration are not sufficient to secure autonomy. For instance, autonomy does not only require the capacity to make informed decisions, but also the ability to critically reflect on the goals we pursue through these informed decisions.

This paper aims to investigate whether such absence is philosophically justified. This philosophical investigation differs from an empirical investigation aiming at explaining why participants in the Jomtien conference decided not to include autonomy in the Declaration. Such empirical investigation would identify normative reasons, but also power relationships and diplomatic stakes. A philosophical investigation restricts its focus on the validity of possible normative justifications for the absence or presence of autonomy in any list of global aims of education. This paper also aims to critically examine the normative validity of positive arguments in favour of the inclusion of autonomy among the educational aims pursued at the global level. In doing so, we could also refine our understanding of the nature and the value of autonomy as an educational aim.

Another prefatory comment is in order. In this paper, 'education' does not necessarily refer to formal education. Formal education is education delivered by professional teachers within institutions such as schools or universities. Formal education is intentional: education is the main goals of students' and teachers' activities. Formal autonomy education involves deliberating seeking to develop autonomy through various learning activities and pedagogical methods. But the development of autonomy might also occur outside of schools through a variety of learning situations, such as conversations or life experiences.

This philosophical investigation, like all philosophical works, starts from a particular, situated standpoint. This is the standpoint of a European person whose cultural and social background makes it highly likely that she will deem 
autonomy valuable. This is also the standpoint of a professional philosopher whose professional environment values rationality, critical thinking, reflexivity, independence of mind, and self-control. For such activity, autonomy is an undeniable asset. This standpoint induces a strong bias in favour of the value of autonomy. Avoiding unjustified or misplaced extrapolations from what is good for oneself to what is good for others is always difficult, and perhaps even more so for an investigation conducted from the well-known philosophical armchair. However, from such diagnosis it does not necessarily follow that we should abandon the project of assessing the normative validity of social and educational aims. But some methodological precautions are in order. First, the philosophical dialectic must fully take into account other possible perspectives. Possible objections and counterarguments should be addressed in the most charitable and convincing way. Second, the normative conclusions in this paper are open to revisions and have the status of pro tanto claims, that is, of claims that could be overridden by superior or more urgent normative considerations. The danger of biases that too often reflect problematic patterns of domination and power relationships is sufficiently great to justify relinquishing the philosophical desire to provide definitive, all-things-considered, normative conclusions. ${ }^{1}$

The paper unfolds as follows: the first section is methodological. It discusses whether the normative issues at stake regarding the permissibility of autonomy education are the same in multicultural nation-states and in the international context. Second, the paper presents a working definition of the key term of 'autonomy'. It will be argued that the definition of autonomy must remain unspecified to leave room for adaptation to a variety of social and cultural context. The third section addresses two major objections to the expansion of autonomy as an educational goal to the global scale: the objection of priority and the objection of cultural imperialism. The paper concludes by providing insights on the potential value of autonomy education in a globalised world.

\section{Autonomy Education in Multicultural States and Autonomy Education in the International Context}

This paper began with the observation that liberal philosophers who defend autonomy as an educational aim in the nation-state context have never addressed the issue of whether autonomy should be an educational aim beyond the borders of the nation-state. Now, one could challenge the paper's ambition to address a gap in the literature by suggesting that the issue of whether autonomy could and should be an educational aim in the international context is analogous to the issue of whether it could and should be an educational aim in

1 The postcolonial critique in particular points to these dangers (Culp, 2019: ch. 7) 
multicultural nation-states. The latter issue has been extensively addressed by political and educational philosophers (Costa, 2011; Feinberg, 1980; Galston, 1995; Gutmann, 1995; Macedo, 2003; MacMullen, 2007; Mookherjee, 2008; Neufeld, 2013; Rawls, 1993: 199; Schouten, 2018; Swaine, 2010; Warnick, 2012). If indeed both problems are analogous, an additional investigation of the desirability of autonomy as a global educational aim seems unnecessary (or at least the only task this paper would have to fulfil is to show that the same normative issues are at stake).

Despite the fact that they exhibit similarities, the two issues are different in significant respects. When liberal philosophers of education argue that autonomy should be an educational aim in liberal states, most of them seem to assume that the state is one of the main agents whose duty is to make sure educational institutions and practices secure the development of future adults' autonomy. In liberal democracies in the North, the state has the monopoly of coercive power (in all, or almost, their territory). In such context, one can reasonably assume the state is an agent capable of imposing a school curriculum and educational practices aiming at rendering people autonomous. Furthermore, liberal philosophers of education generally assume it is desirable that the state be responsible for children's formal education. The question, then, of the desirability of autonomy education at the level of the nation-state becomes the question of the legitimacy of mandatory autonomy education, that is, whether the state can legitimately use its coercive power to either promote or at least facilitate the development of children's capacity for autonomy. The issue becomes especially sensitive in pluralistic societies in which some citizens do not value autonomy, or at least think the kind of autonomy education state schools provide is incompatible with the values they want to transmit to their children.

The issue is different at the global scale. There is no such a thing as a global state. Many nation states are not fully capable of imposing a school curriculum aiming at rendering people autonomous. They lack material and institutional resources. Dictatorial nation-states are likely to be unwilling to educate children to become autonomous and critical citizens. As to non-state actors, the extent to which international instruments such as the Jomtien Declaration are binding depends on the legal nature of the instrument, on the means signatory states have at their disposal to implement it and on the existence of enforcement mechanisms. We should also mention powerful non-state actors such as NGO and multinational corporations. Even if they were capable of and willing to implement mandatory autonomy education policies, one could still question their democratic legitimacy. Therefore, at the global scale, the 
issue of whether autonomy education for all is desirable does not immediately translate into the issue of whether the state (or any analogous powerful agent) can legitimately use its coercive power to impose autonomy education to all. The 'global philosopher of education' must therefore perform separately two tasks the 'national philosopher of education' does simultaneously. The first task consists of determining whether autonomy is a morally desirable educational aim for all current inhabitants of the world. This task is different from the task of ascertaining whether autonomy is a desirable educational aim in multicultural states, because the discussion of the value of autonomy education in such states is usually shaped by the consideration that autonomy education will be mandatory and imposed on groups that reject liberal values. Given the weakness of many states in the world, they might not be capable of imposing autonomy education. This means that the discussion of the value of autonomy education at the global level need not be shaped by the consideration that autonomy education will be implemented through the exercise of the coercive power of the state. The second task consists in determining which agent(s) are capable of deliver autonomy education and control whether children receive adequate autonomy education, and whether these agents are legitimate to perform such task. This paper will address the first task.

We can thus conclude that the issue of autonomy as a global educational aim is different in enough respects from the issue of autonomy as an educational aim in multicultural nation-states to be addressed as such. I now move to another important preliminary step: providing a definition of 'autonomy' and 'education' that serves the purpose of thinking of autonomy as an educational aim.

\section{Autonomy and Education: Working Definitions}

Autonomy is a contested notion. In everyday language, it connotes independence. A child, a patient or an elderly is deemed autonomous if her condition does not prevent her from performing everyday activities by herself, such as walking, dressing and washing herself. Autonomy also connotes Western, modern and capitalist individualism. Many philosophical accounts of autonomy depart from these everyday conceptions of autonomy by emphasising reflexivity rather than activity, or by pointing out its social and relational aspects. There are multiple disagreements among philosophical conceptions of autonomy. These conceptions enter into different philosophical systems and are employed for different purposes. For instance, in moral and political philosophy, autonomy can be used to define morality, as part of justificatory devices aiming at deriving normative political principles, as an ideal to be pursued through political or 
education actions, and so on. ${ }^{2}$ The purpose of this paper is to conceptualise autonomy (i) as a normative educational aim (ii) that can be applied in different cultural and social contexts.

Autonomy as an educational aim is a normative concept, an ideal. It is not something that can be taken for granted, but an individual capacity whose development and exercise can be fostered or hampered by educational policies and practices. Educational policies and practices aimed at autonomy seek to develop the autonomy of the learner, but also to make sure the learner is able and disposed to acknowledge, respect and protect the autonomy of others.

How could we conceptualise autonomy in such a way that it could apply in different cultural and social contexts? A possible method can be to derived from Catriona Mackenzie's suggestion that autonomy is a multidimensional concept (Mackenzie, 2014). According to Mackenzie, whilst a unitary concept has 'a single set of necessary and sufficient conditions for [its] correct application,' a multi-dimensional concept involves more than one set of necessary and sufficient conditions for its application, because its correct application depends on the purpose of such application as well as on the normative and social context in which it is applied. In the discussion of autonomy as an educational aim, we could thus conceive autonomy as a multidimensional concept whose necessary and sufficient conditions of application could vary across different national, social and cultural contexts.

In more concrete terms, insofar as the individual capacity for autonomy admits of degrees, the multidimensional approach could, for instance, admit that the adequate degree of autonomy as a global educational aim would be settled by taking into account its context of application. Hence the necessary and sufficient conditions for an external evaluator to say 'this student is autonomous' or 'this student is being educated for autonomy' would vary across contexts. In some contexts, it would suffice to provide an education aiming at developing a minimal degree of autonomy to say that 'this student is being educated for autonomy'; in others, education would have to target a higher degree of autonomy to be properly labelled as 'education for autonomy'. We could also take into account the fact that some cultures may emphasise certain dimensions of autonomy (say, endorsement and reflexivity) more than others (say, choice). Cultures may also differ in how high they rank autonomy as compared to other moral values, or on their conception in the spheres of human existence in which it is fitting to exercise autonomy (Mookherjee, 2008). A definition of autonomy as a global educational aim would allow for interpretation, adaptation, and

2 As Michael Hand puts it: 'Arguing against autonomy is like trying to slay the Hydra: as soon as one shows the inadequacy of one account, two more spring up in its place.' (Hand, 2006: 536). 
revision, depending on the cultural and social context. More generally, in order to preserve the applicability of the concept of autonomy to a plurality of normative contexts, we must avoid a working definition that relies on too massive metaphysical assumptions or that makes only sense in relation to a fullfledged philosophical system. For example, this definition must not be confused with or assimilated to the Kantian conception of moral autonomy.

However, for the very meaning of 'autonomy' not to become devoid of its content, a guiding ideal seems in order. This guiding ideal amounts to a minimal set of necessary and sufficient conditions for autonomy to apply in any context. Autonomy is an ideal, the ideal of the autonomous person who is 'a (part) author of his own life,'3 that is, who fashions to a meaningful degree important parts of her own life (Raz, 1986: 369). Being the author of one's life does not mean one directs all aspects of one's existence ex nihilo, independently from one's social, cultural and moral background. It does not even necessarily mean one should have multiple options to choose from. ${ }^{4}$ Moreover, having the capacity for autonomy does not require exercising this capacity on every occasion or in every sphere of one's life. The term 'being the author of one's life' refers to the way a person relates to the values and goals that direct her own life. This person may have inherited these values and goals from her family and cultural background. Or she may have opted to pursue values and goals that are foreign to her background. This does not matter to assess her capacity for autonomy. What matters is (i) that she sees these goals as her own, and that (ii) she is able to identify and critically assess her principal reasons for action. Regarding (i), seeing one's goals as one's own means that one does not feel alienated from them. Regarding (ii), the idea of 'critical assessment' can be interpreted in a more or less strong way. The most radical views on the ability to critically assess reasons involve the ability to revise them in a fundamental way. Weaker views involve awareness of these reasons, endorsement of them and the ability to distance oneself from them. By 'fashioning to a meaningful degree important parts of her own life,' I mean that the autonomous person does not just nod at

3 One could wonder whether this conception of autonomy does not dismiss too quickly the fact that humans may have only very little control over their life. The issue depends on what we mean by 'control over one's life.' If we mean 'control over one's actions,' this leads us to the issue of free will, which should be distinguished from autonomy. Discussing the main existing accounts of free will is well beyond the scope of the paper. But it might be interesting to consider that people could be autonomous without having free will, that is, without being able to do otherwise (one of the main understandings of free will). One could, for instance, adhere to her actions, see them as her own and as guided by reasons she endorses, even if she would not have been able to do otherwise. Spinoza's and the Stoics' account of freedom might be akin to this idea (but they are part of a more complex philosophical system and it is impossible to do them justice in a footnote). If, by 'control over one's life,' we refer to the kind of control that is dependent on political, social and economic circumstances, I, like many other political philosophers, make a bet that these circumstances can be changed, and that the degree of control people have over them can be increased through human action.

4 Having access to too many options may even hamper autonomy (Dworkin, 1988: 62-81). 
the decisions pertaining to important parts of her life. Does it imply she should always choose in a nonconformist way her religion, career and partner? Not necessarily. A person could be autonomous and make conventional choices. She could even let other people decide for her. But, in those cases (conformist choices and letting other people choose for oneself), the autonomous person should, first, at least endorse these choices, feel that they are the right kind of choice for her. Second, her mental capacities and dispositions should be such that a scenario in which she would have made less conformist choices would remain psychologically plausible.

\section{Two Objections to the Planet-wide Expansion of the Ideal of Autonomy}

This section addresses some of the major challenges to the inclusion of autonomy among the educational aims endorsed at the global level. This section does not, however, address challenges to the idea that autonomy should be an educational aim in general. These challenges have been extensively discussed in the literature. ${ }^{5}$ Here, I assume the plausibility of the claim that autonomy is a morally desirable educational aim in Western liberal democratic societies and tackle the contested issue of whether it is also a morally desirable educational aim beyond the borders of these Western liberal democratic societies. What are the major objections to autonomy as a global educational aim?

\section{The Priority Objection}

This first objection submits that, given the current global order, autonomy as an educational aim should not be a priority at the global level because it is too costly. There are more pressing educational and non-educational needs to satisfy in the world. This objection presupposes that the economic costs of developing autonomy through education are such that they will divert resources from securing basic needs. This presupposition will be true if autonomy education always involves implementing formal or non-formal educational activities in addition to those required to meet basic learning needs. However, it might be the case that autonomy education has less to do with additional educational activities and more with the way knowledge and skills are taught. An autonomypromoting education is an education that makes available to the learner the reasons for the education she receives (of course, these reasons should be communicated in a way appropriate to the learner's age).

A shift in educational method does not necessarily involve a significant increase in spending. Now, some might point out that the level of autonomy of people who attended tertiary education is likely to be higher, whereas providing everyone with access to higher education is likely to be very expensive. However,

5 Autonomy as a central education aim has been criticized (Galston, 1991; Hand, 2006; Swaine, 2012). 
one could think that exposure to a variety of life experiences is at least as likely to favour the development of autonomy as exposure to theoretical knowledge in the cosseted environment of educational institutions. Second, arguing that autonomy should be an educational aim for all leaves us free to determine the degree of autonomy that should be secured through education. Developing a sufficient degree of autonomy seems more feasible than aiming at maximal autonomy.

But given our ignorance regarding the real economic costs of global autonomy education, let us grant that pursuing autonomy as a global education aim will not be cheap. Then, it is a fact that some countries have more resources to devote to education than others. Some countries can afford autonomy education whilst others cannot. But the real issue is whether we should accept this state of affairs as it is when we reflect on the desirable aims of education. In other words, should material constraints work as a constraint on the truth of the normative claim that autonomy is a desirable education aim for all? ${ }^{6}$ On the one hand, it seems a philosophical account of the global aims of education should be something more than a castle in the air. On the other hand, if Western liberal democracies deem autonomy valuable, it seems unfair and unduly complacent for Western thinkers to deny others the opportunity to benefit from autonomy education because of the global unjust distribution of educational resources. Perhaps the best way to settle the issue is to take into account the purposes and context of application of the normative claim that autonomy should be an educational aim for all. If the use of this normative claim is to be understood as merely evaluative (Gheaus, 2013), or to criticise (Southwood, 2018: 6) Western liberal democracies for failing to transfer sufficient resources and competences to less advantaged countries or people, then it seems fitting not to take into account material constraints. This normative claim can also be used as a normative principle. It is relevant and helpful to formulate normative principles independently from questions of implementation (Barry and Valentini, 2009; Gilabert and Lawford-Smith, 2012: 819-820), among other reasons because it forces us to consider courses of action we might have otherwise neglected. In other words, it forces us to distinguish perceived infeasibility from real infeasibility. Including autonomy rather than basic educational needs in the list of desirable educational goals for all is more likely to lead to questioning the current global distribution of educational resources. The purpose of a philosophical reflection on the global aims of education might not just be to prescribe immediate action, but also to criticize the current order and to stimulate our social and political imagination.

6 I owe this phrasing to Southwood's analysis of feasibility (Southwood, 2018: 5). 
The upshot of the discussion of the Priority Objection is threefold. First, the purpose of normative claims about the aims of education is not just to prescribe immediate educational action among the limited set of actions that are perceived as feasible or cheap. The purpose is to identify an ideal that can have the critical function of distancing us from the status quo and stimulate our imagination to identify actions that are really feasible even if they are not perceived as such. Second, normative claims about autonomy as a global educational aim are sufficiently broad to allow us to adapt our interpretation to their context of application. Third, autonomy as a global educational aim should be understood as sufficient or adequate autonomy, not as maximal autonomy.

\section{The Cultural Imperialism Objection}

Martha Nussbaum, a capability theorist and a philosopher of education, has already defended the claim that education at the global level should not only secure basic literacy and numeracy (Nussbaum, 2011: 155). Nussbaum, however, views human capabilities rather than autonomy as the primary aim of education. It is not the aim of this paper to discuss the relationship between capabilities and autonomy education. ${ }^{7}$ I would rather like to emphasise the reasons why Nussbaum avoids arguing for autonomy as a global educational aim. In part, Nussbaum endorses political liberalism in her later works, and political liberalism tends to be suspicious of uses of the state's coercive power to promote through education a conception of autonomy that involves more than the autonomy-related knowledge and skills needed to secure the stability of liberal institutions (Nussbaum, 2011). ${ }^{8}$ Since this first concern pertains to the discussion of whether autonomy should be an educational aim within liberal democracies and is already extensively discussed in the literature (Brighouse, 1998; Callan, 2004; Fowler, 2011; Galston, 1991; Gutmann, 1987; Schouten, 2018), I will not discuss it here. But Nussbaum's reluctance to endorse autonomy as a global educational aim is also due to her concern over the risk of value-imperialism ( Nussbaum, 2011: 101). She explicitly distanced herself from autonomy-based liberalism (such as Raz's perfectionist liberalism) on the grounds that autonomy 'is a definite political value in the Western tradition with a specific anti-theocratic history' (Nussbaum, 2010). Hence her choice of the

7 Autonomy education could be viewed as part of capability education. Or capabilities could be understood as conditions for autonomy (Mackenzie, 2014), or comprehensive autonomy as a condition for the development and exercise of capabilities (Ferracioli and Terlazzo, 2014). But a rich account of autonomy and of its conditions could also compete and conflict with the capability aim for education. For a critique of Nussbaum's rejection of mandatory comprehensive autonomy-promoting education, see Drerup (Drerup, 2016).

8 Nussbaum argues that the sole conception of autonomy the state should promote is not to promote "comprehensive autonomy,' but 'political autonomy,' which in her view seems to refer to: (i) the disposition to show respect for other citizens, including those who affirm conceptions of the good life that differ from one's own, and to protect spaces in which they can live by their own values; (ii) having been taught about options regarding different conceptions of the good life. 
label 'practical reason' (rather than 'autonomy') to refer to the central human capability of being able to form and critically revise a conception of the good (Nussbaum, 2011: 34). The general objection that autonomy as an educational goal is unfitting for non-Western parts of the world actually encompasses several different objections, and it seems helpful to disentangle them.

\section{A First Variation on the Cultural Imperialism Objection: Autonomy is not a} Universal Value

Some could point out that autonomy is not a universal value. It belongs to the Western tradition and, the objection continues, it is therefore only suited to Western contexts. ${ }^{9}$ In response, let me first stress that the premise that autonomy belongs only to the Western tradition should not be too easily taken for granted. Before anything else, the notion of 'Western tradition' is vague in multiple ways. The very frontiers of the 'West' are unclear. Are the Ancient Greeks part of it, despite the fact that they seemed to have more interactions with the Middle East, Asia, and Africa than with Western and Northern Europe? ${ }^{10}$ Should we consider Islamic civilisation as part of Western civilisation, insofar as they seem to have major characteristics in common (a monotheist religion, the influence of Greek philosophy etc.)? ${ }^{11}$ The recently emerged field of Global History challenges the Eurocentric bias in the humanities and emphasises the significance of overseas circulations and connexions for our understanding of the past (Conrad, 2016). The notion of 'Western tradition' is also unclear in that it does not make explicit whose tradition we are referring to. It does indeed seem that autonomy is a crucial notion in the Western tradition of moral philosophy (Schneewind, 1998). But it could be the case that autonomy only belongs to the Western intellectual elite tradition, not to the values endorsed by Western laypeople.

In addition to the ambiguities of the notion of 'Western tradition' itself, there is abundant indication that autonomy, or a value akin to it, might also be part of non-Western traditions. Jack Goody cites the work of Nur Yalman, an anthropologist, who writes that freedom and equality are fundamental values in Islam (Goody, 2006: 257; Yalman, 2001). According to Yalman, in Islam, a person's worth should depend on her intentions, behaviour, and piety, which she is considered free to control, not on her social or ethnic background. Relying on psychoanalytic research on cross-cultural comparisons, Sawitri Saharso

9 Although this line of thought might not have been endorsed by philosophers, or at least philosophers working in the analytical tradition, it seems to me sufficiently widespread to deserve a discussion. For example, when I teach a class on autonomy or liberal values, students almost inevitably raise this objection. However, if the reader thinks this is not a philosophically interesting argument, he or she can move to the next variation on the cultural imperialism objection.

10 Martin Bernal's Black Athena, which has triggered many debates among historians, emphasises the significance of the influence of African (Egyptian) and Semitic (Phoenician) civilisations on Ancient Greek civilisation (Bernal, 1987).

11 As Jack Goody puts it, 'One of the most disturbing myths of the west is that the values of our 'Judeo-Christian' civilization have to be distinguished from the east in general and from Islam in particular. For Islam has the same roots as Judaism and Christianity as well as many of the same values.' (Goody 2006, 240). 
suggests that, despite the fact that they are socialized in a culture that seems, at first glance, to place low value on individuality and autonomous choice, South Asian women are well-equipped to better develop the mental abilities required for the exercise of autonomy (Saharso, 2000). Drawing from Katherine Ewing's taxonomy (Ewing, 1991), she distinguishes between interpersonal autonomy and intrapsychic autonomy. Interpersonal autonomy refers to the capacity to make autonomous choices in the world, including nonconformist choices. Intrapsychic autonomy is the ability to develop an inner world and mental representations of 'sources of self-esteem and comfort' which enable the agent to cope with her environment. Whilst interpersonal autonomy is highly valued in European and North American contexts, intrapsychic autonomy seems more developed among South Asian people. Scholars in Confucianism suggest that there are elements in Confucius' writings that coincide with certain conceptions of moral autonomy or certain aspects thereof. These dimensions include the voluntary endorsement of morality, a reflective engagement in moral life (Chan, 2002), self-cultivation and the exercise of autonomous judgment and choice of action in conforming to the right norms and commands for human behaviour (the Heaven's Dao) (Brindley, 2011). Paul Radin's interviews with Winnebago sages (intellectuals), as well as Paulin Hountondji or Henry Odera Oruka's own interviews of African intellectuals, challenge the prejudice that African and Native American philosophy encouraged unanimity of judgment within the community (Hountondji, 1996; Oruka, 1990; Radin, 1927). They have shown that there is ample room for disagreement and for the development of a plurality of views in African communities, which implies that these communities value the development and exercise of critical judgment and thinking skills.

It thus seems autonomy, or a notion akin to it appears in several world cultures. However, a justification of the inclusion of autonomy among global education aims by appealing to the presence of autonomy or autonomy-related values in world cultures runs into several problems. The first problem is the risk of confirmation bias. This is the risk of selectively searching and emphasising information about cultures that confirm the hypothesis we wish to validate the hypothesis that autonomy is a value endorsed in all cultures (note that this is also a problem for those who wish to validate the hypothesis that autonomy is the exclusive property of Western cultures, and that other cultures are more communitarian, hierarchical, etc). The second problem is that this justification derives a normative conclusion ('autonomy should be a global educational aim') from a factual statement ('autonomy is valued in all societies'). A fact does not in itself constitute a reason to affirm the validity of a moral judgment. We need other reasons, reasons that are themselves evaluative or normative, to support 
the claim that autonomy should be an educational goal for all, and it might be that these reasons are not different for Africans, Americans, Asians, and Europeans. If these problems call into question our response to the objection that autonomy is not a universal value, they also call into question the objection itself. For, from the fact that the value that autonomy is not universally endorsed, one could not derive the conclusion that autonomy should not be promoted at the universal level. Now, inquiring the value of autonomy into different moral traditions may nevertheless be pertinent not for the justification of autonomy, but for its application into concrete contexts. Citizens of different countries might appreciate the fact that they can find in their own tradition that autonomy is a valuable aim. This would motivate them to adhere to this ideal. We could conceive a justification of autonomy as a global educational aim that would be valid at the global level, and at the same time emphasise culture-dependent reasons that could motivate the inhabitants of different parts of the world to adhere to the ideal of autonomy as an educational aim.

\section{A Second Variation on the Cultural Imperialism Objection: Cultural Domination}

The second variation on the objection of cultural imperialism stresses the problematic character of the postcolonial relationship between the Western world and its counterparts to support the hypothesis that we should avoid transplanting Western values in non-Western contexts. In other words, even if autonomy could in itself be a suitable value for non-Western contexts, the whole history of cultural relationships between the (often formerly colonial) West and the (often formerly colonised) non-West is too tainted for importations of Western philosophical values to be considered without suspicion. Furthermore, affirming the value of autonomy-promoting education might implicitly amount to express the judgment that autonomy-promoting cultures are morally superior to other cultures (Parekh, 1997: 59).

These concerns might be mitigated by the discussion of the preceding version of the objection, which has challenged the preconception that autonomy is the exclusive property of the West. However, even if it is empirically untrue that autonomy is absent from non-Western moral traditions and that all Western people value autonomy, and even if the value of autonomy could be justified without appealing to the authority of Western philosophical traditions, we should not underestimate the fact that the association between autonomy and the West remains significant for many people today. Now, if relations between the West and other parts of the world had always been peaceful and egalitarian, this would not be a problem. The borrowing of a 'foreign' value would be perceived as innocuous and even enriching. But it is understandable to be wary of the promotion of a value that is perceived not just as foreign, but 
as originating from colonial powers that have reaped the wealth of colonised territories, perpetrated crimes and massacres, and promoted the ideology of the racial, cultural and moral inferiority of the colonised. Moreover, education has been used to facilitate and legitimate colonial domination (Culp, 2019: ch. 7).

There seem to be at least two possible ways out of this problem. The first could consist of reflecting on word choices. Perhaps it would be helpful to define an education aim akin to autonomy but to describe it with a vocabulary less closely associated to European Enlightenment and in a non-European language. The second way out of the problem emphasises the political and emancipatory dimension of the ideal of autonomy. Autonomy entails the alleviation of unjustified coercion, manipulation (Raz, 1986: 377-8), and oppression (Friedman, 2003). Autonomy is therefore incompatible with colonialism, that is, with 'the subjugation of one people to another.' Collective autonomy is incompatible with colonialism, insofar as colonisation involves the conquest, control, government and administration of colonised territories without the consent of those who are conquered, controlled, governed and administrated. But colonialism and postcolonial relationships between formerly colonised and colonisers are also irreconcilable with individual autonomy in several ways. Colonial and postcolonial arrangements can involve arbitrary interferences of colonising powers with the choices of individual members of colonised societies. For example, if the terms of the uranium mining contract between Areva (renamed Orano), the French multinational specialised in nuclear energy, and the Nigerien state, had been fairer, ${ }^{12}$ Nigeriens would have had access to a greater share of the share of the benefits of uranium extraction and thereby to enhanced economic and social opportunities.

Colonial and postcolonial ideologies also undermine what MacKenzie calls the 'self-authorisation' dimension of autonomy (Mackenzie, 2014: 104-5). Selfauthorisation involves the belief and judgment that I have normative authority to exercise control over my destiny, that I am competent and legitimate to establish the values with which I identify and to determine my reasons for action. For a person to regard herself as having normative authority over her destiny, she needs to be recognised as such by others (Anderson and Honneth, 2005). If she is regarded as being a member of an (allegedly) inferior cultural or racial group, she is unlikely to develop the self-authorisation dimension of autonomy. As Kymlicka puts it, our self-respect can be seriously damaged if the culture we identify with is despised or belittled (Kymlicka, 1995: 89). Yet colonial and postcolonial ideologies are precisely grounded on the idea of racial

12 According to Oxfam, in 2010 Niger received only 13\% of the export value of the uranium extracted by Areva on its territory. 
or - more recently - cultural hierarchy, that is, the idea that some cultures (and thus, the people who identify with them) are less worthy of respect than others and need 'civilising.' Because autonomy requires self-authorisation and recognition, autonomy-promoting education cannot consistently amount to such 'civilising missions.'

One could, however, worry that, even if autonomy education does not mean to be the 'civilising mission' of the colonial era and does have truly emancipatory ambitions, it could, like colonial civilising missions, uproot communities that do not value autonomy and cause irremediable damages to their social fabric. It is difficult to address this worry without knowing the concrete details of the case at hand. We would need to know the social dynamics and power relationships of this particular society before autonomy education is introduced as well as the nature and importance of the 'costs' of transitioning to a society that values autonomy. But condemning autonomy education just because it may change traditional societies seems to involve a bias in favour of the status quo. On the other hand, if autonomy education leads to the extinction of valuable social practices and relationships, this is a good reason not to implement it. As I said in the introduction, the claim that autonomy education is valuable for all is a pro tanto claim, which can be overridden by other normative considerations. Why a pro tanto claim (rather than the status of an all-things considered claim)? Because, as citizen of former colonial powers, it does not seem fitting to grant the claims I defend the status of action-guiding, all-things-considered, judgments. They just provide reasons to value certain normative goals, such as autonomy. These reasons are to be discussed and debated both inside and outside of philosophical circles, and it seems crucially important to invite all those who are likely to be concerned in the conversation.

A Third Variation on the Cultural Imperialism Objection: is Autonomy too Secular?

A third objection on the objection of cultural imperialism echoes Nussbaum's concern with the anticlerical and secularist history of the value of autonomy. The objection runs as follows: the value of autonomy is a secular value, and not just a secular value. It has also anticlerical and antitheocratic connotations that render it unfit to cultural contexts in which religion is important. Moreover, its promotion amounts to express disrespect towards believers, or at least uncritical believers. Insofar as many societies in the world are not as much secularised as the West, the promotion of autonomy beyond the borders of Western liberal democracies might lead to unsuitable and even disrespectful educational policies and practices. 
As to the moral and philosophical traditions that led Western societies to value autonomy, it seems that religious conceptions such as liberal Protestantism were at least as crucial as secular Enlightenment. Now, one could point out that, regardless of its intellectual genealogy, the concept of autonomy itself involves the rejection of religious authority. Autonomy, the objector would continue, means that the individual agent should regard herself as the only normative authority over herself, thereby excluding religious normative authorities, such as the authority of God or of the priest, rabbi or imam.

This objection shows why it is interesting to leave the concept of autonomy open to revisions. For it is one thing to be the only normative authority over oneself, and it is another to have normative authority over oneself. Being a source of normative authority is probably a necessary condition for autonomy. But being the only source of normative authority would entail an excessively demanding conception of autonomy. We rely on other normative authorities all the time. If I want to build a house, I rely on the normative authority of my architect.

However, it is true that, if the exercise of autonomy does not preclude religion, it does preclude certain ways of relating oneself to religion (but also to nonreligious worldviews such as political views). It precludes adherence to religious or philosophical creeds, doctrines, and norms based on fear, anxiety, unsecure attachment or blind obedience. This does not mean the exercise of autonomy requires a strenuous reflection on one's higher-order reasons for believing in God; nor does it require shopping around to choose whichever existing religion or philosophy better match one's deeply held convictions (this does not mean the exercise of autonomy precludes such endeavours either; the extent to which one chooses to reflectively engage with religious beliefs rather than with, say, alternative methods to raise honeybees is itself an exercise of autonomy). An adequate degree of autonomy exercise can be reached if the agent is aware of her reasons for adhering to her conception of the good, if she endorses this conception and if she could critically distance herself from it if needed. Imagine, for instance, a young Muslim woman who practices her religion. She prays, fasts during Ramadan and plans to go to Mecca on pilgrimage. Her religion matters to her not because she has critically examined each of the verses of the Quran, but because she has been raised in a religious and loving family. She cherishes her sense of belonging to her parents' communities and the memories associated with religious festivals and gatherings. She is aware of this, and she fully identifies with Islam. The core Islamic values of equality and solidarity speak to her. But she has sufficient emotional security, critical thinking skills, and self-trust to be fully able to distance herself from the threats and directives 
of some fellow believers who affirm that she does not practice 'proper Islam' and who mean, by that, a literal and rigid interpretation of Islam. According to the account of autonomy propounded in this paper, this young woman is sufficiently autonomous in the way she relates to her religion.

\section{Conclusion}

This paper has argued that autonomy could pro tanto be considered a valuable educational aim to be pursued at the global levels. After having emphasised that the issue of the value of autonomy education at the global level raises issues that are distinct from the issues raised by the imposition of autonomy education in pluralistic nation-states, the paper has argued that autonomy as a global educational ideal should be understood as a multidimensional concept whose necessary and sufficient conditions for application could vary across contexts, Finally, the paper has tackled two objections to the thesis that autonomy is a valuable educational aim at the global level: the objection of priority and three versions of the objection of cultural imperialism.

This discussion does not exhaust all the possible objections to the planetwide expansion of the value of autonomy through education. But, by way of conclusion, I shall rather provide elements for a positive case for autonomy education in a context that exceeds the borders of Western liberal democracies. These insights do not, in themselves, constitute a full-fledged case for the value of global autonomy education, but they might encourage further reflection and debate.

Firstly, global autonomy education could benefit from encounters between different cultural conceptions of autonomy. Students who have been socialised in an environment that praises choice and immediate gratification are likely to benefit from learning how to cultivate intrapsychic autonomy. Students whose mental environment facilitates the development of the 'inner citadel' may build on these mental capacities to develop a conception of themselves as a person who can make choices that might not always conform the expectations of others. Autonomy as a global educational aim is valuable because it encourages us to broaden our understanding of autonomy. This broadening renders the ideal of autonomy suitable to different cultures. Moreover, it increases the likelihood that autonomy will contribute to personal flourishing and political and social emancipation. ${ }^{13}$

Secondly, most modern societies across the world are confronted with consumerism. 'Consumerism' refers to a combination of societal norms and

13 These brief remarks call for a more detailed assessment of the way autonomy education might contribute to gender equality, which I have no space to address here. 
practices that dispose individuals to acquire material goods in ever-greater quantities. Consumerism is problematic for global and intergenerational justice because it leads to consumption levels that involve the depletion of scarce resources and the degradation of the environmental conditions people across the world need to live well. At first glance, one might think the spirit of autonomy education is more likely to support consumerism than to counter it. One could point out that the emphasis of autonomy theorists on options sides with a consumer model of choice. ${ }^{14}$ However, engrained features of consumer societies are actually threats to the exercise of autonomy (Schinkel et al., 2010). The media and advertising industry glorify those who give way to impulses, instant gratification, and ephemeral euphoria, not those who embrace self-control, long-term planning and the conscious prioritisation of their commitments (Schinkel et al., 2010: 281-2). Whilst autonomy education involves teaching consumers the knowledge and character traits needed to make choices that are in line with the values and commitments they genuinely endorse, not choices that are in line with the profit goals of multinationals. ${ }^{15}$

\section{the global justicenetwork}

14 E.g. (Burtt, 2003: 184).

15 This paper was presented at the 'Global Justice in and through Education' conference organised by Julian Culp at the American University of Paris. I am grateful to participants for their questions and remarks. I also wish to thank two anonymous reviewers for their comments. All remaining errors are my own. 


\section{References}

Anderson J and Honneth A (2005) Autonomy, Vulnerability, Recognition and Justice. In: Christman J and Anderson J (eds) Autonomy and the Challenges to Liberalism. Cambridge: Cambridge University Press, pp. 127-149.

Barry C and Valentini L (2009) Egalitarian challenges to global egalitarianism: a critique. Review of International Studies 35(3): 485-512.

Bernal M (1987) Black Athena: The Afroasiatic Roots of Classical Civilization. New Brunswick, N.J.: Rutgers University Press.

Brighouse H (2006) On Education. London; New York: Routledge.

Brindley E (2011) Moral autonomy and individual sources of authority in the Analects. Journal of Chinese Philosophy 38(2): 257-273.

Burtt S (2003) Comprehensive Educations and the Liberal Understanding of Autonomy. In: McDonough K and Feinberg W (eds) Citizenship and Education in Liberal-Democratic Societies: Teaching for Cosmopolitan Values and Collective Identities. Oxford: Oxford University Press.

Callan E (2004) Creating Citizens: Political Education and Liberal Democracy. Oxford: Oxford University Press.

Chan J (2002) Moral Autonomy, Civil Liberties, and Confucianism. Philosophy East and West 52(3): 281-310.

Conrad S (2016) What Is Global History? Princeton, NJ: Princeton University Press.

Costa MV (2011) Rawls, Citizenship, and Education. London: Routledge.

Culp J (2019) Democratic Education in a Globalized World: A Normative Theory. London: Routledge.

Curren R (2013) A neo-Aristotelian account of education, justice, and the human good. School Field 11(3): 231-249.

Drerup J (2016) Liberalism without Perfection? Autonomy, Toleration and Education in Nussbaum's Capability Approach. Ethical Perspectives 23(1): 41-71.

Dworkin G (1988) The Theory and Practice of Autonomy. Cambridge: Cambridge University Press.

Ewing K (1991) Can psychoanalytical theory explain the Pakistani woman? Ethos (19): 131-160.

Feinberg J (1980) The Child's Right to an Open Future. In: Aiken W and La Follette H (eds) Whose Child? Children's Rights, Parental Authority, and State Power. New Jersey: Rowman \& Littlefield.

Ferracioli L and Terlazzo R (2014) Educating for Autonomy: Liberalism and Autonomy in the Capabilities Approach. Ethical Theory and Moral Practice 17(3): 443-455.

Friedman M (2003) Autonomy, Gender, Politics. Oxford University Press. 
Galston WA (1991) Liberal Purposes: Goods, Virtues, and Diversity in the Liberal State. Cambridge: Cambridge University Press.

Galston WA (1995) Two Concepts of Liberalism. Ethics 105(3): 516-534.

Gheaus A (2013) The Feasibility Constraint on The Concept of Justice. The Philosophical Quarterly 63(252): 445-464.

Gilabert P and Lawford-Smith H (2012) Political Feasibility: A Conceptual Exploration. Political Studies 60(4): 809-825.

Goody J (2006) The Theft of History. Cambridge; New York: Cambridge University Press.

Gutmann A (1987) Democratic education. Princeton, NJ: Princeton University Press.

Gutmann A (1995) Civic Education and Social Diversity. Ethics 105(3): 557-579.

Hand M (2006) Against Autonomy as an Educational Aim. Oxford Review of Education 32(4): 535-550.

Hountondji PJ (1996) African Philosophy: Myth and Reality. 2nd edition (1st edition in French 1976, 1st edition in English 1983). Bloomington Ind: Indiana University Press.

Kymlicka W (1995) Multicultural Citizenship: A Liberal Theory of Minority Rights. Oxford; New York: Oxford University Press; Clarendon Press.

Levinson M (2002) The Demands of Liberal Education. Oxford: Oxford University Press.

Macedo S (1990) Liberal Virtues: Citizenship, Virtue, and Community in Liberal: Citizenship, Virtue and Community in Liberal Constitutionalism. Oxford; New York: Clarendon Press, OUP.

Macedo S (2003) Diversity and Distrust: Civic Education in a Multicultural Democracy.

Cambridge, MA: Harvard University Press.

Mackenzie C (2014) Three Dimensions of Autonomy: a Relational Analysis. In: Veltman A and Piper M (eds) Autonomy, Oppression, and Gender. Oxford: Oxford University Press, pp. 15-41.

MacMullen I (2007) Faith in Schools? Autonomy, Citizenship, and Religious Education in the Liberal State. Princeton, NJ: Princeton University Press.

Mookherjee M (2008) Autonomy, Force and Cultural Plurality. Res Publica (14): 147-168.

Neufeld B (2013) Political Liberalism and Citizenship Education. Philosophy Compass 8(9): 781-797.

Nussbaum MC (2010) Political Liberalism and Respect: A Response to Linda Barclay. SATS 4(2): $25-44$.

Nussbaum MC (2011) Creating Capabilities: The Human Development Approach. Cambridge, MA: Belknap Press of Harvard University Press.

Nussbaum MC (2011) Perfectionist Liberalism and Political Liberalism. Philosophy and Public Affairs 39(1): 3-45.

Oruka HO (1990) Sage Philosophy: Indigenous Thinkers and Modern Debate on African Philosophy. Leiden u.a.: Brill. 
Parekh B (1997) Dilemmas of a Multicultural Theory of Citizenship. Constellations 4(1): 54-62.

Radin P (1927) Primitive Man As Philosopher. D. Appleton And Company. Available at: http:// archive.org/details/primitivemanaspho31975mbp (accessed 21 November 2018).

Rawls J (1993) Political Liberalism. New York: Columbia University Press.

Raz J (1986) The Morality of Freedom. Oxford: Clarendon Press.

Saharso S (2000) Female autonomy and cultural imperative: two hearts beating together. In: Kymlicka W and Norman W (eds) Citizenship in Diverse Societies. Oxford: Oxford University Press, pp. 224-242.

Schinkel A, de Ruyter D and Steutel J (2010) Threats to autonomy in consumer societies and their implications for education. School Field 8(3): 269-287.

Schneewind JB (1998) The Invention of Autonomy: A History of Modern Moral Philosophy. Cambridge: Cambridge University Press.

Schouten G (2018) Political liberalism and autonomy education: Are citizenship-based arguments enough? Philosophical Studies 175(5): 1071-1093.

Southwood N (2018) The Feasibility Issue. Philosophy Compass 13(8): e12509.

Swaine L (2010) Heteronomous Citizenship: Civic Virtue and the Chains of Autonomy. Educational Philosophy and Theory 42(1): 73-93.

Swaine L (2012) The False Right to Autonomy in Education. Educational Theory 62(1): 107-124.

Warnick BR (2012) Rethinking Education for Autonomy in Pluralistic Societies. Educational Theory 62(4): 411-426.

White J (1982) The Aims of Education Restated. London; New Work: Routledge.

Yalman N (2001) Further observations on love (or equality). In: Warner J (ed.) Cultural Horizons. Syracuse, NY: Syracuse University Press. 